\title{
Life cycle assessment considering water-energy nexus for lithium nanofiltration extraction technique
}

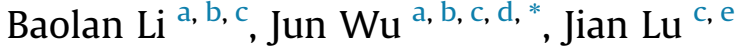 \\ ${ }^{a}$ Key Laboratory of Comprehensive and Highly Efficient Utilization of Salt Lake Resources, Qinghai Institute of Salt Lakes, Chinese Academy of Sciences, \\ Xining, Qinghai 810008, China \\ ${ }^{\mathrm{b}}$ Qinghai Provincial Key Laboratory of Geology and Environment of Salt Lakes, Xining, Qinghai, 810008, China \\ ${ }^{c}$ University of Chinese Academy of Sciences, Beijing, 100049, China \\ d School of Resources and Environmental Engineering, Ludong University, Yantai, Shandong, 264025, China \\ ${ }^{\text {e } C A S ~ K e y ~ L a b o r a t o r y ~ o f ~ C o a s t a l ~ E n v i r o n m e n t a l ~ P r o c e s s e s ~ a n d ~ E c o l o g i c a l ~ R e m e d i a t i o n, ~ Y a n t a i ~ I n s t i t u t e ~ o f ~ C o a s t a l ~ Z o n e ~ R e s e a r c h ~(Y I C), ~ C h i n e s e ~ A c a d e m y ~ o f ~}$ \\ Sciences (CAS) Shandong Key Laboratory of Coastal Environmental Processes, YICCAS, Yantai Shandong 264003, China
}

\section{A R T I C L E I N F O}

\section{Article history:}

Received 5 January 2020

Received in revised form

5 March 2020

Accepted 15 March 2020

Available online 19 March 2020

Handling Editor: Panos Seferlis

\section{Keywords:}

Lithium nanofiltration extraction technique

Water and energy consumption

Life cycle assessment

Environmental impact

\begin{abstract}
A B S T R A C T
Lithium is an important strategic resource and the Qinghai-Tibet Plateau possesses abundant liquid lithium resources in the salt lakes. Nanofiltration is a promising technique for lithium extraction from salt-lake brines. However, no information on the environmental impact of lithium nanofiltration extraction is available. This study used life cycle assessment (LCA), life cycle cost (LCC) and water consumption (LCWC) methods to evaluate the environmental burden of lithium nanofiltration extraction technique with the functional unit of $1 \mathrm{~kg} \mathrm{Li}_{2} \mathrm{CO}_{3}$ products. The results showed that nanofiltration stage was the key process to produce the environment burden based on higher values of global warming potential, acidification potential, photochemical ozone creation potential, soot \& ashes, and nutrient enrichment in comparison with the other stages of lithium extraction. Electricity consumption was the major contributor to global warming potential. The total life cycle cost was 18.01 USD with internal cost accounting for $99.99 \%$. Direct water consumption was 22 times higher than indirect water consumption in this process. The water and energy consumption of nanofiltration stage accounted for $98.05 \%$ and $53.95 \%$ of total consumption, respectively. The total cost of energy and water consumption for nanofiltration technique in different regions followed the order of Tibet $>$ Inner Mongolia $>$ Sinkiang $>$ Qinghai. This study provided quantitative data and theoretical basis for lithium resource exploitation in the ecologically-fragile regions in the world.
\end{abstract}

(c) 2020 Elsevier Ltd. All rights reserved.

\section{Introduction}

As the lightest metal element in nature, lithium is electrochemically active with the highest redox potential value and the highest specific heat capacity in the solid elements to become the perfect material for battery, glass, ceramics and photoelectricity industry (Sun et al., 2015; Swain, 2017). Lithium resources including brines and high-grade lithium ores for commercial lithium production have been found in several parts of the world (Swain, 2017). It is currently in urgent needs to extract lithium from brines due to

\footnotetext{
* Corresponding author. Key Laboratory of Comprehensive and Highly Efficient Utilization of Salt Lake Resources, Qinghai Institute of Salt Lakes, Chinese Academy of Sciences, Xining, Qinghai, 810008, China.

E-mail address: wujunlisa@163.com (J.Wu).
}

the increasing demand for lithium and more than $60 \%$ of the global lithium products are produced from brines (Tadesse et al., 2019). China and Chile have significant lithium resources. Lithium is an important strategic resource and mainly distributed in the QinghaiTibet Plateau of China with $\mathrm{LiCl}$ total reserves of $15.2 \times 10^{6} \mathrm{t}$ and $80 \%$ of lithium resource existing in the salt lakes of Qaidam Basin (Shi et al., 2018; Song et al., 2014; Yu et al., 2013). Therefore, it is important to discuss the potential environmental impact of lithium extraction from brines in the Qinghai-Tibet Plateau since this region is ecologically fragile although it possesses rich lithium resource.

Lithium extraction from brines generally includes 3 major processes: preparation of lithium-rich brine, separation of magnesium and lithium, and precipitation of lithium carbonate. Moreover, the separation of magnesium and lithium is the critical step in lithium extraction. The technologies widely used for extracting lithium 
from salt-lake brines include precipitation, ion-exchange, liquidliquid extraction, and membrane process. The main principle of precipitation process is to firstly remove calcium, magnesium and manganese, and then $\mathrm{Na}_{2} \mathrm{CO}_{3}$ is added. Finally, more than $99 \%$ of $\mathrm{Li}_{2} \mathrm{CO}_{3}$ products can be obtained after evaporation. The ion exchange method employs the specially-prepared resin/aluminate/ ion-exchanger to efficiently recover lithium from brines. Liquidliquid extraction is conducted by an extractant to recover lithium. These methods are relatively simple while the consumption of chemical reagents and energy is relatively high (Swain, 2017). Lithium was reported to be recovered as crystalline $\mathrm{Li}_{2} \mathrm{CO}_{3}$ with purity of $99.55 \%$ using the brine collected from Salar de Uyuni of Bolivia by the precipitation process (An et al., 2012). Ion exchange coupled with liquid-liquid extraction was used to recover lithium with a $\mathrm{Li}^{+}$flux of $1.67 \times 10^{-8} \mathrm{~mol} /\left(\mathrm{cm}^{2} \mathrm{~s}\right)$ to keep stable production state for over 50 days (Song et al., 2014). Lithium was extracted from salt-lake brine by liquid-liquid extraction process using N523TBP-FeCl 3 to reach the extraction rate of 96\% (Shi et al., 2018).

Membrane process is a relatively new technology which has been applied in drinking water treatment (Bonton et al., 2012; Giagnorio et al., 2018), water softening (Bergman, 1995), seawater desalination (Al-Shayji and Aleisa, 2018), industrial wastewater treatment (Alcaina-Miranda et al., 2009), and leachate treatment (Chaudhari and Murthy, 2010). In recent years, membrane process as a promising lithium extraction technique has been gradually used to extract lithium from salt lakes because this technique allows univalent ions to pass through the membrane to trap divalent/ polyvalent ions. The relatively advanced processes including reverse osmosis (RO) and nanofiltration (NF) have been applied for preconcentration/separation of lithium from brine. Separation of lithium and magnesium from brine using a desalination nanofiltration membrane has been performed (Sun et al., 2015). The results indicated that magnesium and lithium separation was highly dependent on the $\mathrm{pH}$, operating pressure, and $\mathrm{Mg}^{2+} / \mathrm{Li}^{+}$ ratio. The competitive coefficient was susceptible to the $\mathrm{Mg}^{2+} / \mathrm{Li}^{+}$ ratio which should be less than 20 (Sun et al., 2015).

Life cycle assessment (LCA) is a useful technology and method for evaluating the environmental impact of a product during its entire life cycle including the acquisition of raw materials, the production process, the use pathways, and disposal of the product (Chang et al., 2014). Different aspects including raw material demand, product yields, and waste disposal have become the critical factors influencing LCA results. Aiming at understanding and evaluating the potential environmental impacts of a system throughout the life cycle of the product, LCA has been widely used in building construction (Oh et al., 2017), agricultural products (Aganovic et al., 2017), and chemicals (Hong et al., 2014).

LCA in lithium industry has shown different application aspects. A cradle-to-gate LCA was conducted for its production by rockbased technology (LRT) compared with the brine-based technology (LBT) with the result showing that the impacts of LRT were dominated by the leaching process and higher than those of LBT (Jiang et al., 2020). LCA has been used to evaluate the environmental impacts of different supply options for lithium carbonate $\left(\mathrm{Li}_{2} \mathrm{CO}_{3}\right)$ required for producing Li-ion batteries as well as the influence associated with the electric vehicles (Stamp et al., 2012). A system dynamic model was established to evaluate three resilient mechanisms of the lithium supply chain (Shao and Jin, 2020). Other LCA applications mainly focused on lithium batteries (Cusenza et al., 2019; Lipu et al., 2018; Marques et al., 2019) and the recovery of lithium from discarded electronics (He et al., 2020; Islam et al., 2020). Although the environmental impact of conventional lithium extraction methods has been paid attention (Flexer et al., 2018; Jiang et al., 2020), information on LCA of lithium extraction is still limited. Therefore, it is very important to evaluate the environmental influence of lithium extraction from salt lakes since lithium resource exploitations have been increasingly performed in the Qinghai-Tibet Plateau. Moreover, the impact of water and energy consumption is important for the lithium resource utilization in the Qinghai-Tibet Plateau. This study performed LCA for lithium extraction using nanofiltration technique to discuss the possible environmental impact of this technique. The final objectives of this study are to figure out the potential environmental impacts of a prospective technique of lithium resource exploitation and to provide the theoretical basis for industry planning and environmental management in the Qinghai-Tibet Plateau and similar highelevation areas.

\section{Nanofiltration extraction of lithium from salt-lake brine}

Designed according to the previous report (Li et al., 2019), the nanofiltration process adopted in this study mainly included dilution, nanofiltration, hyperfiltration, electrodialysis, mechanical vapor recompression (MVR) evaporation, and precipitation \& dry stages. The raw brines from a salt lake in Qinghai Province of China were used after removing boron due to complicated composition. The concentration of lithium and magnesium in the raw brine was 0.58 and $5.68 \mathrm{~g} / \mathrm{L}$, respectively. The $\mathrm{Mg}-\mathrm{Li}$ ratio of the raw brine was 9.86 .

Critical process of lithium extraction is to separate the lithium from the brines with high $\mathrm{Mg}$-Li ratio using nanofiltration membranes (Kang et al., 2014; Sun et al., 2015). Membrane fouling is the frequent problem during nanofiltration extraction of lithium due to high-concentration salts in brine. Therefore, the raw brine should be firstly diluted with fresh water in the dilution tank and pass through nanofiltration membrane unit for separation.

The nanofiltration membrane material used in this process was commercial DK4040 purchased from GE Company with the maximum operating pressure of $4.14 \mathrm{MPa}$ (Kang et al., 2014). The brines were fed to pass through the membrane units after dilution stage. Inlet pressure and concentrated water flow in membrane unit were adjusted by inlet valve and outlet valve and monitored through the pressure gauge and flow meter, respectively. Separation efficiency of this process reached the best with the operating pressure of $3.4 \mathrm{MPa}$ and the dilution ratio of 15 based on the previous study (Kang et al., 2014; Sun et al., 2015). The solution with high-content lithium was further concentrated by reverse osmosis, electroosmosis membrane, and evaporation process. MVR evaporator that was capable of reducing the external energy consumption by reusing the energy produced from steam was adopted for further evaporation. Finally, sodium carbonate was added to precipitate lithium carbonate and lithium carbonate products were obtained after drying process. The mass flow of lithium nanofiltration extraction technique was shown in Fig. 1.

\section{Materials and methods}

\subsection{Functional unit and system boundary}

The functional unit can provide quantitative data for all related input and output of target process so that it is the basis for comparative analysis on life cycle inventory (LCI). In this study, evaluation on all raw materials, energy consumption, and wastes were based on the functional unit of $1 \mathrm{~kg} \mathrm{Li}_{2} \mathrm{CO}_{3}$ product since the lithium nanofiltration extraction application is still at lab/pilot scale. Nanofiltration membrane lithium extraction process discussed in this study included the stages of raw material dilution, nanofiltration separation, hyperfiltration, electrodialysis, MVR evaporation, and $\mathrm{Li}_{2} \mathrm{CO}_{3}$ precipitation. The influential factors involved raw material consumption, energy consumption, and 
waste emissions. The system boundary and material flow of lithium nanofiltration extraction technique were shown in Fig. 1.

\subsection{Methodology, LCI, and data sources}

LCA focuses on evaluating the use of natural resources and environmental pollution. It is important to identify the key factor affecting the ecosystem and put forward the corresponding suggestions for improving rational exploitation of salt-lake resources. LCA on lithium extraction from salt lakes only considered the impact on the ecosystem and resource consumption because the exploitation and production of lithium resources in salt lakes possessed simple process, short transportation distance, and waste disposal without occupying lands. Therefore, eight kinds of environmental pollutants $\left(\mathrm{CO}_{2}, \mathrm{CH}_{4}, \mathrm{SO}_{2}, \mathrm{NO}_{\mathrm{X}}, \mathrm{N}_{2} \mathrm{O}, \mathrm{CO}, \mathrm{VOC}\right.$, and $\left.\mathrm{PM}_{10}\right)$ and five kinds of environmental impact assessment indicators including global warming potential (GWP), acidification potential (AP), photochemical ozone creation potential (POCP), soot and ashes (SA), and nutrient enrichment (NE) were selected for LCA on lithium nanofiltration extraction. The emission of individual pollutant in each impact type was weighted by emission coefficient to obtain a uniform unit value for analyzing each category of environmental impact. The emission coefficients and water consumption coefficient of various energy sources referred to Chinese life cycle database (CLCD) (Liu et al., 2010). The analysis of life cycle cost (LCC) and life cycle water consumption (LCWC) in this study was performed on the basis of the system boundary of LCA and the calculation model referred to the previous study (Xiang, 2016).

The environmental pollutants selected in this study included $\mathrm{CO}_{2}, \mathrm{CH}_{4}, \mathrm{SO}_{2}, \mathrm{NO}_{\mathrm{X}}, \mathrm{N}_{2} \mathrm{O}, \mathrm{CO}, \mathrm{VOC}$ and $\mathrm{PM}_{10}$. The emission of pollutants was calculated by the following Eq. (1):

$M_{p}=\sum_{s=1}^{5} \sum_{j=1}^{2} E C_{s, j} E F_{p, j}$

where $M_{p}, p, S, \mathrm{j}, E C$ and $E F$ represent the pollution emissions,

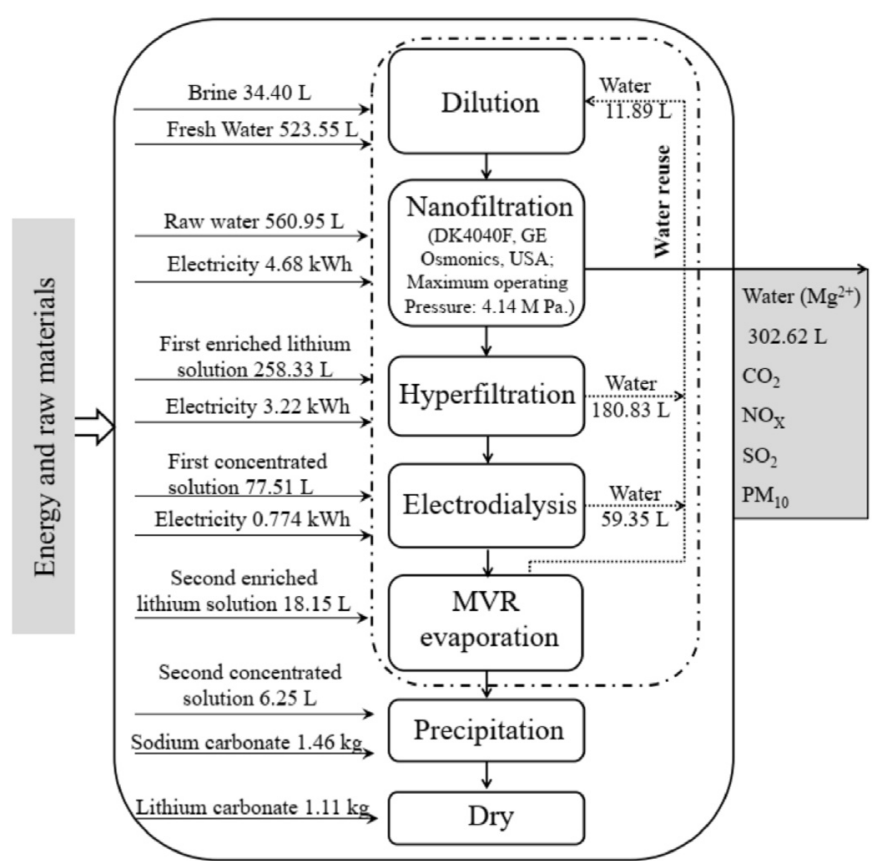

Fig. 1. System boundary and process flow of lithium nanofiltration extraction technique. pollutant, process stages, types of energy, energy quality and emission coefficient, respectively.

The environmental impact assessment indexes included GWP, $\mathrm{AP}, \mathrm{POCP}, \mathrm{SA}$, and NE. The individual index was calculated by the following Eqs. (2)-(5):

$G W P=M_{\mathrm{CO}_{2}}+23 M_{\mathrm{CH}_{4}}+296 M_{\mathrm{N}_{2} \mathrm{O}}$

$A P=M_{\mathrm{SO}_{2}}+0.7 M_{\mathrm{NO}_{X}}$

$P O C P=0.6 M_{V O C}+0.03 M_{C O}+0.01 M_{C_{4}}$

$N E=0.35 M_{N O_{X}}$

where the unit of GWP, AP, POCP, NE and SA were $\mathrm{kg} \mathrm{CO}_{2}$ eq (equivalent quantity), $\mathrm{kg} \mathrm{SO}_{2}$ eq, $\mathrm{kg} \mathrm{C}_{2} \mathrm{H}_{4}$ eq, $\mathrm{kg} \mathrm{NO}$ X eq, and $\mathrm{kg}$ $\mathrm{PM}_{10}$, respectively.

LCC, targeting at solving the economic problems the enterprises concerning about, is divided into internal costs $\left(\mathrm{LCC}_{\mathrm{In}}\right)$ that is the traditional product cost and external costs $\mathrm{LCC}_{\mathrm{Ex}}$ ) that is the monetized environmental impact of the product system. Cost of the nanofiltration membrane device with the price of about 29,100 USD generally accounts for the most of process cost. However, the function unit in this study was $1 \mathrm{~kg} \mathrm{Li}_{2} \mathrm{CO}_{3}$ products, which was a small yield and belonged to small trial scale. Therefore, the loss and maintenance of equipment were not considered in this study. LCC only focused on the raw materials and energy consumption during the production process. The calculation of LCC referred to Eqs. (6)-(8):

$L C C=L C C_{I n}+L C C_{E x}$

$L C C_{\text {In }}=C_{e}+C_{w}+C_{s}$

$L C C_{E x}=\sum_{i}^{8} U E_{x_{i}} E_{q_{i}}$

where $C_{e}, C_{w}, C_{s}, i, E_{q_{i}}$, and $U E_{x_{i}}$ represent electric power cost, water consumption cost, sodium carbonate cost, pollutants, pollutant emission and external cost of the pollutant, respectively.

LCWC analysis includes direct water $\left(\mathrm{LCWC}_{\text {direct }}\right)$ that refers to the amount of fresh water used in the production process and indirect water consumption ( $\mathrm{LCWC}_{\text {indirect }}$ ) that stands for the consumption of water resources caused by energy consumption. LCWC was calculated by the following Eqs. (9) and (10):

$L C W C=L C W C_{\text {direct }}+L C W C_{\text {indirect }}$

$L C W C_{\text {indirect }}=\sum_{i=1}^{5} \sum_{j=1}^{2} E C_{i, j} W C F_{j}$

where $i, j, E C_{i, j}$, and $W C F_{j}$ represent process stages, types of energy, energy quality and water consumption coefficient, respectively.

The LCI was derived from the previous study (Kang et al., 2014; Sun et al., 2015), and then the data were converted according to functional unit. The LCI of lithium nanofiltration extraction included all the consumption of brine, water, and electricity (Fig. 1) as well as all possible environmental emissions (Fig. 2). The detailed LCI data referred to Table 1. Energy consumption was calculated by the power and duration of the equipment used. The usage of sodium carbonate was calculated according to the chemical equation: $2 \mathrm{LiCl}+\mathrm{Na}_{2} \mathrm{CO}_{3}=2 \mathrm{NaCl}+\mathrm{Li}_{2} \mathrm{CO}_{3}$. This process evaluated by this study increased the amount of sodium carbonate by $10 \%$ and 


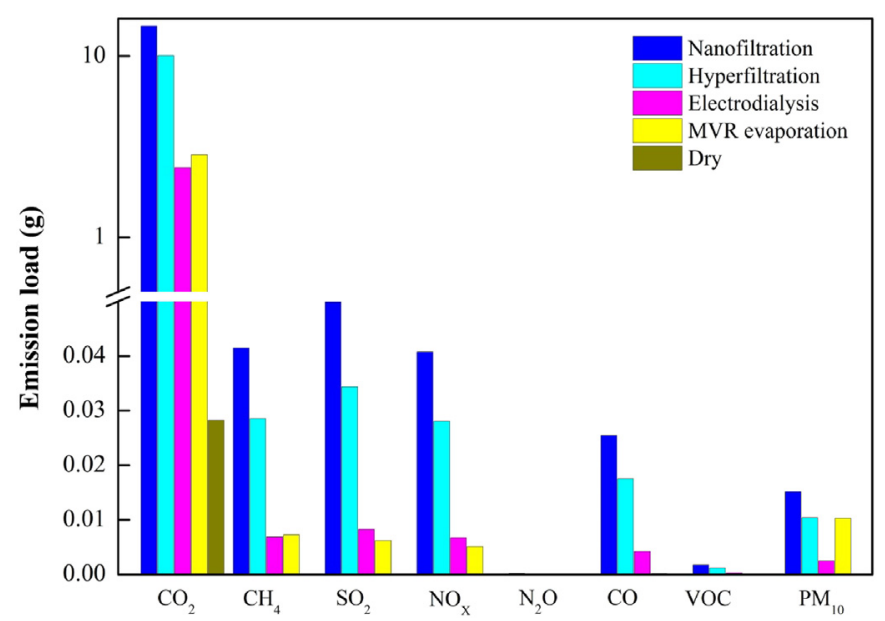

Fig. 2. Pollutant emissions at individual stage of lithium nanofiltration extraction technique.

allowed all lithium ions to precipitate. The inventory of LCC and LCWC was mainly obtained from cost investigation (i.e., market price of electricity, water and sodium carbonate) and the market prices were adopted (based on July 16 of 2019 with exchange rate of $1.0 \mathrm{USD}=6.87 \mathrm{CNY}$ ) by this study.

\section{Results and discussion}

\subsection{Life cycle impact assessment analysis}

LCI analysis obtained the environmental emission at different stages of the lithium nanofiltration extraction technique (Fig. 2). Environmental emission at the nanofiltration stage was the largest, and then followed by that at hyperfiltration stage. Emission amount followed the order of nanofiltration $>$ hyperfiltration $>$ MVR evaporation>electrodialysis $>$ dry for $\mathrm{CO}_{2}, \mathrm{CH}_{4}, \mathrm{~N}_{2} \mathrm{O}$, and $\mathrm{PM}_{10}$ while that followed the order of nanofiltration $>$ hyperfiltration $>$ electrodialysis $>$ MVR evaporation $>$ dry for the remaining pollutants. Emission amounts of $\mathrm{N}_{2} \mathrm{O}$ and VOC were significantly lower than those of other pollutants while emission amount of $\mathrm{CO}_{2}$ at different stages was significantly higher than that of the remaining pollutants. Dry stage generally had the lowest emissions. $\mathrm{CO}_{2}$ emission at dry stage was only $0.19 \%$ of that at nanofiltration stage. $\mathrm{CO}_{2}, \mathrm{CH}_{4}, \mathrm{SO}_{2}$ and $\mathrm{NO}_{\mathrm{X}}$ were the main pollutants with relatively high emission amounts. The environmental emission of this process followed the order of $\mathrm{CO}_{2}>$ $\mathrm{SO}_{2}>\mathrm{CH}_{4}>\mathrm{NO}_{\mathrm{X}}>\mathrm{CO}>\mathrm{PM}_{10}>\mathrm{VOC}>\mathrm{N}_{2} \mathrm{O}$.

The environmental impact indexes at different stages calculated based on the environmental emissions were shown in Fig. 3. GWP was the highest index in the lithium nanofiltration extraction technique with $1.56 \times 10^{-2}, 1.08 \times 10^{-2}$, and $2.59 \times 10^{-3} \mathrm{~kg} \mathrm{CO}_{2}$ eq at nanofiltration, hyperfiltration and electrodialysis stages, respectively. POCP reached $2.21 \times 10^{-6}, 1.52 \times 10^{-6}$, and $3.65 \times 10^{-6} \mathrm{~kg} \mathrm{C}_{2} \mathrm{H}_{4}$ eq at nanofiltration, hyperfiltration and electrodialysis stages, respectively. Compared with the other stages, nanofiltration stage accounted for the largest proportion with $7.85 \times 10^{-5} \mathrm{~kg} \mathrm{SO}_{2}$ eq for $\mathrm{AP}, 5.5 \times 10^{-5} \mathrm{~kg} \mathrm{NO}$ eq for $\mathrm{NE}$, and $1.51 \times 10^{-5} \mathrm{~kg} \mathrm{PM} 10$ for $\mathrm{SA}$, respectively. Nanofiltration stage contributed to $48.79 \%$ of GWP, $50.52 \%$ of AP, $51.84 \%$ of POCP, $50.49 \%$ of NE, and $39.36 \%$ of SA, respectively. The environmental emissions and environmental impact indexes at different stages showed the similar trend of nanofiltration>hyperfiltration>electrodialysis> MVR evaporation>dry. The nanofiltration and hyperfiltration stages generally produced large quantity of environmental load. The major contributing factor of environmental load at these two stages was power consumption based on the key process identification. Compared with the traditional lithium extraction process, nanofiltration membrane process was more environmentally friendly since it did not directly consume large amounts of fossil resources. The main energy consumption of nanofiltration extraction process was electricity and some auxiliary devices such as high-pressure pumps were used to consume lots of energy. Therefore, major environmental load of lithium nanofiltration extraction technique was power consumption. Moreover, steam loss and dust generation during evaporation and dry processes were also considered as components of the environmental load. Similar results in other industrial processes were also reported. Previous study regarding LCA of water treatment plants reported that treatment plant with nanofiltration unit exerted less environmental impact than the conventional treatment plant (Bonton et al., 2012). Power supply was proved to be the most important item influencing the nanofiltration plant targeting at removing chromium in water (Giagnorio et al., 2018). Membrane with covalent binding also had

Table 1

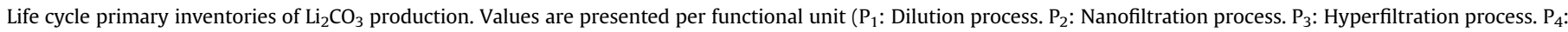
Electrodialysis process. $\mathrm{P}_{5}$ : MVR evaporation process. $\mathrm{P}_{6}$ : Precipitation process. $\mathrm{P}_{7}$ : Dry process).

\begin{tabular}{|c|c|c|c|c|c|c|c|c|}
\hline Categories & Sub-categories & $\mathrm{P}_{1}$ & $\mathrm{P}_{2}$ & $\mathrm{P}_{3}$ & $\mathrm{P}_{4}$ & $\mathrm{P}_{5}$ & $\mathrm{P}_{6}$ & $\mathrm{P}_{7}$ \\
\hline \multirow[t]{9}{*}{ Materials (L) } & Brine & 34.40 & & & & & & \\
\hline & Fresh Water & 523.55 & & & & & & \\
\hline & Raw water & & 560.95 & & & & & \\
\hline & First enriched lithium solution & & & 258.33 & & & & \\
\hline & First concentrated solution & & & & 77.51 & & & \\
\hline & Second enriched lithium solution & & & & & 18.15 & & \\
\hline & Second concentrated solution & & & & & & 6.25 & \\
\hline & Lithium carbonate & & & & & & & 1.11 \\
\hline & Sodium carbonate $(\mathrm{kg})$ & & & & & & 1.46 & \\
\hline \multirow[t]{2}{*}{ Energy } & Electricity $(\mathrm{kWh})$ & & 4.68 & 3.22 & 0.774 & & & \\
\hline & Steam $(\mathrm{g})$ & & & & & & & 110.63 \\
\hline \multirow[t]{8}{*}{ Emissions to air (g) } & $\mathrm{CO}_{2}$ & & 14.62 & 10.06 & 2.42 & 2.86 & & $2.82 \times 10^{-2}$ \\
\hline & $\mathrm{CH}_{4}$ & & $4.15 \times 10^{-2}$ & $2.85 \times 10^{-2}$ & $6.86 \times 10^{-3}$ & $7.24 \times 10^{-3}$ & & $7.16 \times 10^{-5}$ \\
\hline & $\mathrm{SO}_{2}$ & & $4.99 \times 10^{-2}$ & $3.43 \times 10^{-2}$ & $8.25 \times 10^{-3}$ & $6.21 \times 10^{-3}$ & & $6.14 \times 10^{-5}$ \\
\hline & $\mathrm{NO}_{\mathrm{X}}$ & & $4.08 \times 10^{-2}$ & $2.81 \times 10^{-2}$ & $6.74 \times 10^{-3}$ & $5.13 \times 10^{-3}$ & & $5.07 \times 10^{-5}$ \\
\hline & $\mathrm{N}_{2} \mathrm{O}$ & & $2.21 \times 10^{-4}$ & $1.52 \times 10^{-4}$ & $3.66 \times 10^{-5}$ & $4.49 \times 10^{-5}$ & & $4.44 \times 10^{-7}$ \\
\hline & $\mathrm{CO}$ & & $2.55 \times 10^{-2}$ & $1.75 \times 10^{-2}$ & $4.22 \times 10^{-3}$ & $1.74 \times 10^{-4}$ & & $1.72 \times 10^{-6}$ \\
\hline & VOC & & $1.71 \times 10^{-3}$ & $1.18 \times 10^{-3}$ & $2.83 \times 10^{-4}$ & $1.46 \times 10^{-4}$ & & $1.44 \times 10^{-6}$ \\
\hline & $\mathrm{PM}_{10}$ & & $1.51 \times 10^{-2}$ & $1.04 \times 10^{-2}$ & $2.50 \times 10^{-3}$ & $1.03 \times 10^{-2}$ & & $1.02 \times 10^{-4}$ \\
\hline Emissions to water & Water $\left(\mathrm{Mg}^{2+}\right)(\mathrm{L})$ & & 302.62 & & & & & \\
\hline
\end{tabular}




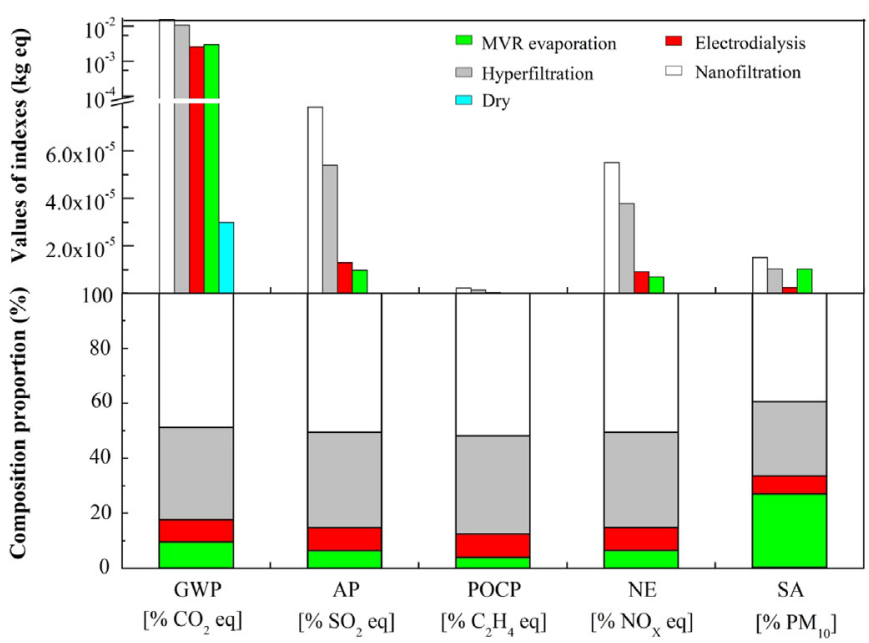

Fig. 3. Distribution and contribution of environmental impact assessment index at individual stage of lithium nanofiltration extraction technique.

much lower environmental impacts than activated carbon made from coal for water membrane purification system (Manda et al., 2014). LCA study on multicrystalline silicon photovoltaic cell production exhibited that it was crucial to increase the use proportion of renewable sources of energy and to improve the consumption efficiency of power generation since energy consumption mainly contributed to the high-score global warming potential (Hong et al., 2016).

\subsection{Life cycle cost analysis}

LCC analysis can effectively reflect the economic rationality of the process to determine whether a process is economically friendly (Ye et al., 2018). Therefore, LCC analysis was used to discuss possible cost of lithium nanofiltration extraction technique (Fig. 4).

The cost of the precipitation reached 17 USD to account for $94.41 \%$ of internal cost during the whole process although this stage only produced a little environmental load and emission. Cost of nanofiltration and hyperfiltration accounted for $80.37 \%$ of external cost. with 41.91\%. PM10, NOX, and SO2 emissions accounted for the similar proportion of LCCEx. Emission of the other pollutants only accounted for a small fraction of LCCEx. Expenditure on treating NOX, SO2 and PM10 was ascribed to the main factor of LCCEx. In general, LCCEx of the process was much less than LCCIn. Therefore, improvement of resource utilization efficiency and dust-removing equipment will significantly reduce the environmental governance costs and increase life cycle economic performance. Similar suggestion was also proposed by the other study (Ye et al., 2018). A hybrid assessment of LCA and LCC for ceramic tile production was performed to show that the total cost of $\$ 2.77 / \mathrm{m} 2$ was mainly caused by the use of raw materials and enhancement of resource utilization efficiency was effective for decreasing the environmental cost in this industry (Ye et al., 2018).

\subsection{Water-energy consumption and water mass balance analysis}

Raw brine must be diluted before nanofiltration membrane separation to prevent the membrane fouling. Extraction of $1 \mathrm{~kg}$ $\mathrm{Li}_{2} \mathrm{CO}_{3}$ requires more than $500 \mathrm{~L}$ fresh water for dilution and large quantity of energy is consumed in the nanofiltration, hyperfiltration and electrodialysis stages based on the investigation. Water resource is very precious in northwestern China since this region is generally arid. Moreover, energy consumption is an important factor influencing the successful operation of a technique. Therefore, the water and electricity consumption at different stages were calculated (Fig. 5). The total water consumption reached $546.51 \mathrm{~L}$ for producing $1 \mathrm{~kg} \mathrm{Li}_{2} \mathrm{CO}_{3}$ with the direct water consumption in the production process of $523.55 \mathrm{~L}$ that was 22 times higher than indirect water consumption in this process. Indirect water consumption was reported to account for a larger proportion in total water consumption of olefins production (Xing et al., 2016), which was contrary to the results of this study. Water/energy consumption at nanofiltration stage accounted for $98.05 \% / 53.95 \%$ of corresponding total consumption. A little water and no electricity were consumed at MVR evaporation stage.

The main substance circulating in the process is water so that it is necessary to make a mass balance of water in the extraction process. Eqs. (11) and (12) were used to determine the water mass balance:

$\left.\begin{array}{c}W_{r 0}+ \\ W_{f 1}\end{array}\right\} \underset{560.89}{\Rightarrow} \underbrace{\text { Nanofiltration }}_{W_{\mathrm{Mg}^{2}+}(302.62 \mathrm{~L})} \underset{258.33}{\Rightarrow} \underbrace{\text { Hperfiltration }}_{W_{f 2}(180.83 \mathrm{~L})} \underset{77.51}{\Rightarrow} \underbrace{\text { Electrodialysis }}_{W_{f 3}(59.35 \mathrm{~L})} \underset{18.9}{\Rightarrow} \underbrace{\text { MVR Evaporation }}_{W_{f 4}(11.89 \mathrm{~L})} \underbrace{\Rightarrow}_{6.25}$ Precipitation

The total LCC was 18.01 USD with LCC $_{\text {In }}$ accounting for $99.99 \%$. $\mathrm{LCC}_{\text {In }}$ played an important role in the life cycle cost. The cost of water, $\mathrm{Na}_{2} \mathrm{CO}_{3}$ and electricity in $\mathrm{LCC}_{\text {In }}$ reached $0.31,17$, and 0.68 USD, respectively. The largest proportion $(94.39 \%)$ of LCC $_{\text {In }}$ was the consumption of $\mathrm{Na}_{2} \mathrm{CO}_{3}$ used in the lithium deposition stage. Electricity and water expenditure covered $3.9 \%$ and $1.7 \%$ of total internal cost, respectively. As a result, $\mathrm{Na}_{2} \mathrm{CO}_{3}$ was the key factor affecting the internal cost to deserve careful selection during the extraction process. $\mathrm{Na}_{2} \mathrm{CO}_{3}$ used in this study was industrial grade with purity of $99 \%$ and its price was relatively high. Therefore, the cost of lithium nanofiltration extraction technique would significantly decrease if the non-industrial $\mathrm{Na}_{2} \mathrm{CO}_{3}$ or other agents could be used as alternative.

$\mathrm{CO} 2$ emission accounted for the largest proportion of LCCEx
$W_{r 0}+W_{f 1}=W_{M g^{2+}}+W_{f 2}+W_{f 3}+W_{f 4}+6.25(L)$

where $W_{r 0}, W_{f 1}, W_{M g^{2+}}$ indicate raw brine material, fresh water used to dilute brine, and magnesia ionized water used in nanofiltration separation, respectively; $W_{f 2}, W_{f 3}$ and $W_{f 4}$ represent the water separated from hyperfiltration, electrodialysis, and MVR evaporation, respectively.

The total amount of brines and fresh water reached $560.95 \mathrm{~L}$ before the nanofiltration separation. Water containing concentrated $\mathrm{Mg}^{2+}$ after separation process accounting for $54 \%$ of the total water was not involved in further process and was used for further magnesium extraction. A total $6.25 \mathrm{~L}$ of solution after hyperfiltration, electrodialysis and MVR evaporation stages was obtained to contain $27.8 \mathrm{~g} / \mathrm{L}$ of $\mathrm{Li}^{+}$. The fresh water separated in 


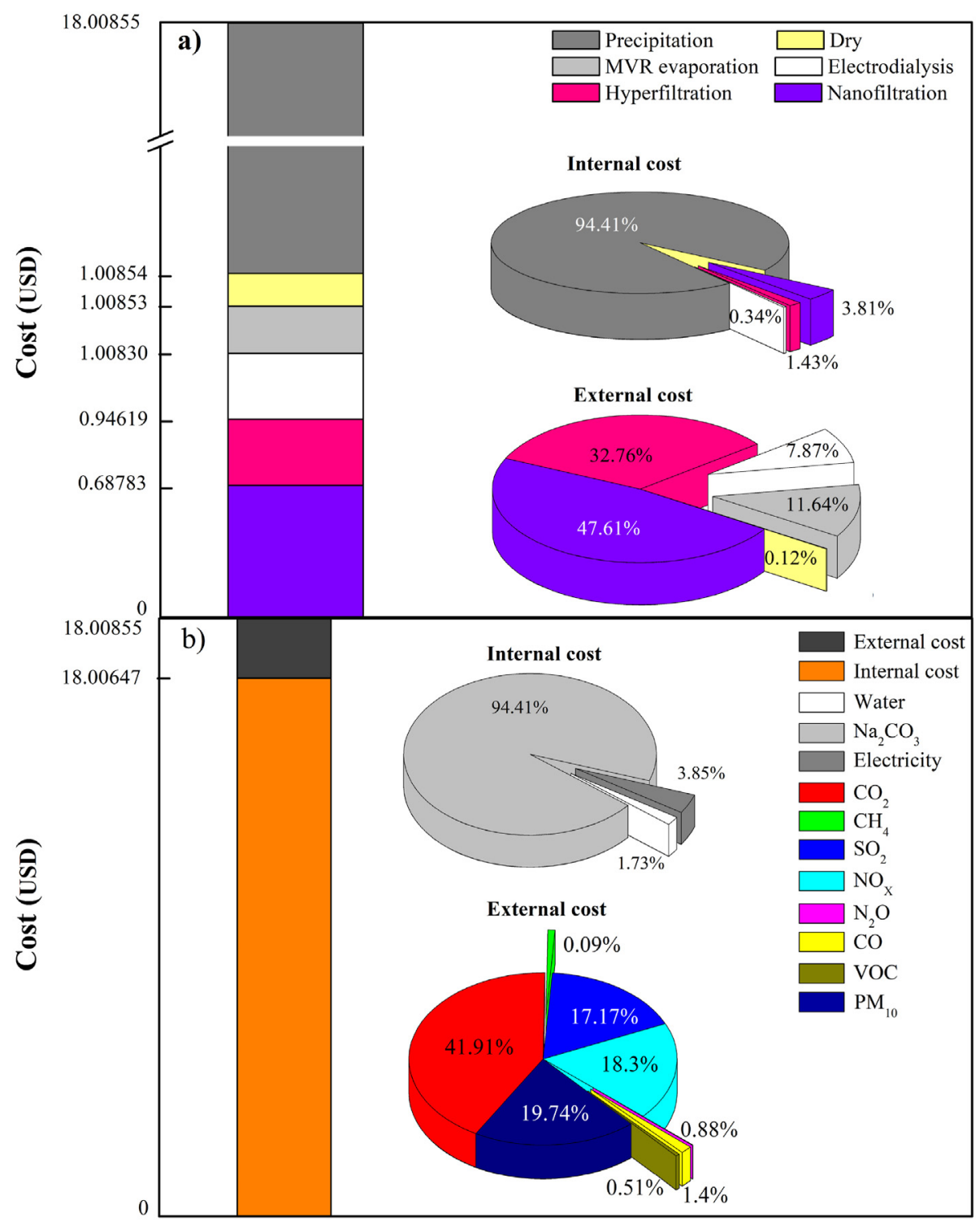

Fig. 4. The life cycle cost at different stages (a) as well as the internal and external cost (b) of lithium nanofiltration extraction technique.

hyperfiltration, electrodialysis and MVR evaporation stages was 180.83 L, 59.35 L and 11.89 L, respectively. The fresh water could be recycled to dilute the brines. In addition, $180.83 / 59.35 \mathrm{~L}$ of solutions with low ion content were separated at hyperfiltration/electrodialysis stage, accounting for $33.09 \% / 10.86 \%$ of the direct water consumption. Water separated at hyperfiltration/electrodialysis stages could also be recycled for diluting the raw brines.

\subsection{Water-energy nexus analysis}

Water-energy nexus analysis on lithium nanofiltration extraction technique was shown in Fig. 6. The detailed data were also exhibited in Table 2. The most important resources consumed in the lithium nanofiltration extraction process were water and energy. Salt lakes are also distributed in Sinkiang, Inner Mongolia, and Tibet of China. Therefore, this study evaluated the water-energy consumption of lithium nanofiltration extraction technique in the study area and these 3 provinces by setting the lithium yields as 1 ton. The price of water and electricity in different province referred to statistical database (NBS, 2019). The water and electricity consumption for producing $1 \mathrm{t} \mathrm{Li}_{2} \mathrm{CO}_{3}$ reached $546.51 \mathrm{t}$ and 8674 Kwh, respectively.

Several provinces in China are exploring the lithium resources from salt lakes, including Sinkiang, Inner Mongolia, Qinghai and Tibet. The water resources of Sinkiang, Inner Mongolia, Qinghai, and Tibet were $58,81,89$ and $362 \mathrm{~km}^{3}$-water $/ \mathrm{m}^{2}$-land, respectively. The consumption of non-domestic water in Sinkiang, Inner Mongolia, and Tibet is charged by 2 -step water price with the second step price higher than the first step price while nondomestic water in Qinghai is charged by the identical price. Therefore, the cost of water consumption in 3 provinces were calculated based on step water prices. Based on the first step price, the water cost for producing $1 \mathrm{t} \mathrm{Li}_{2} \mathrm{CO}_{3}$ in Sinkiang, Inner Mongolia, Qinghai, and Tibet was 159.04, 186.87, 145.52, and 122.46 USD, respectively. In contrast, the water cost according to the second step price for producing $1 \mathrm{t} \mathrm{Li}_{2} \mathrm{CO}_{3}$ in Sinkiang, Inner Mongolia, Qinghai, and Tibet reached 262.41, 279.90, 145.52, and 183.69 USD, respectively. The water consumption cost of Tibet and Qinghai were relatively low under the same production scale. Therefore, Qinghai and Tibet were more economically friendly for application of 


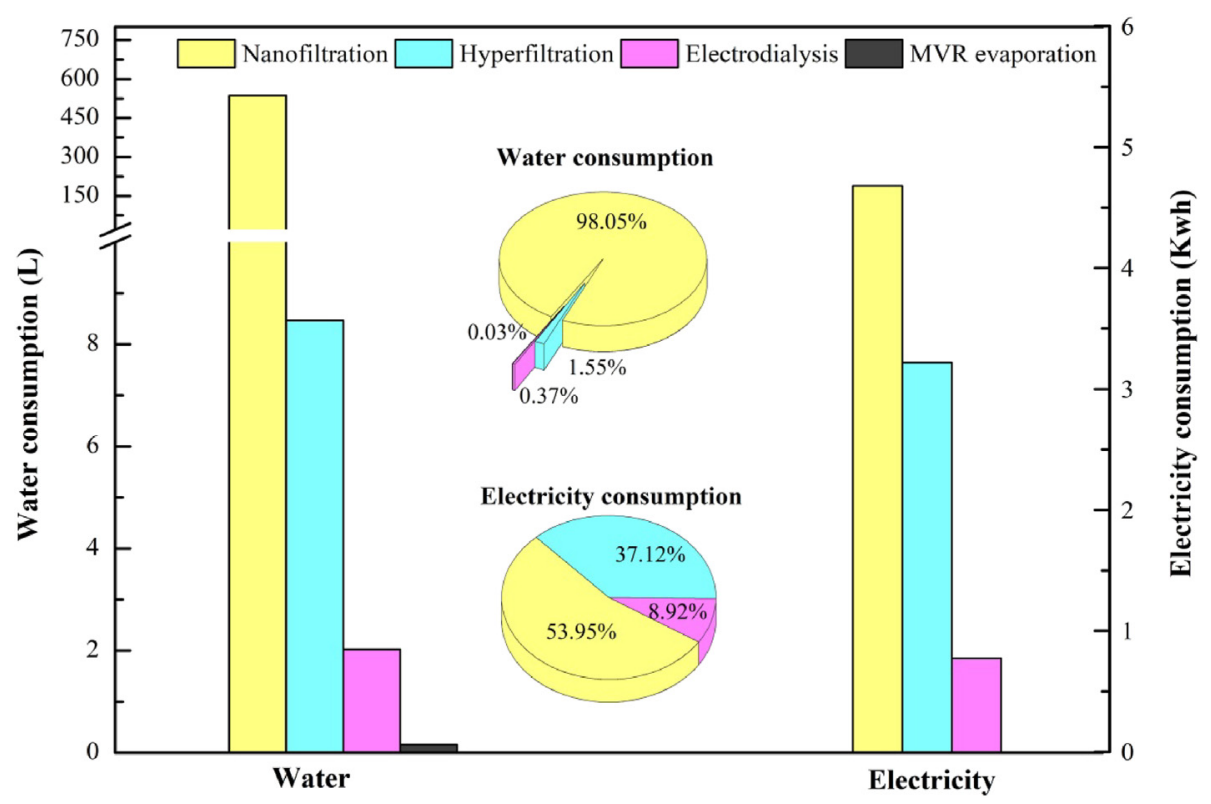

Fig. 5. Water and energy consumption of lithium nanofiltration extraction technique.

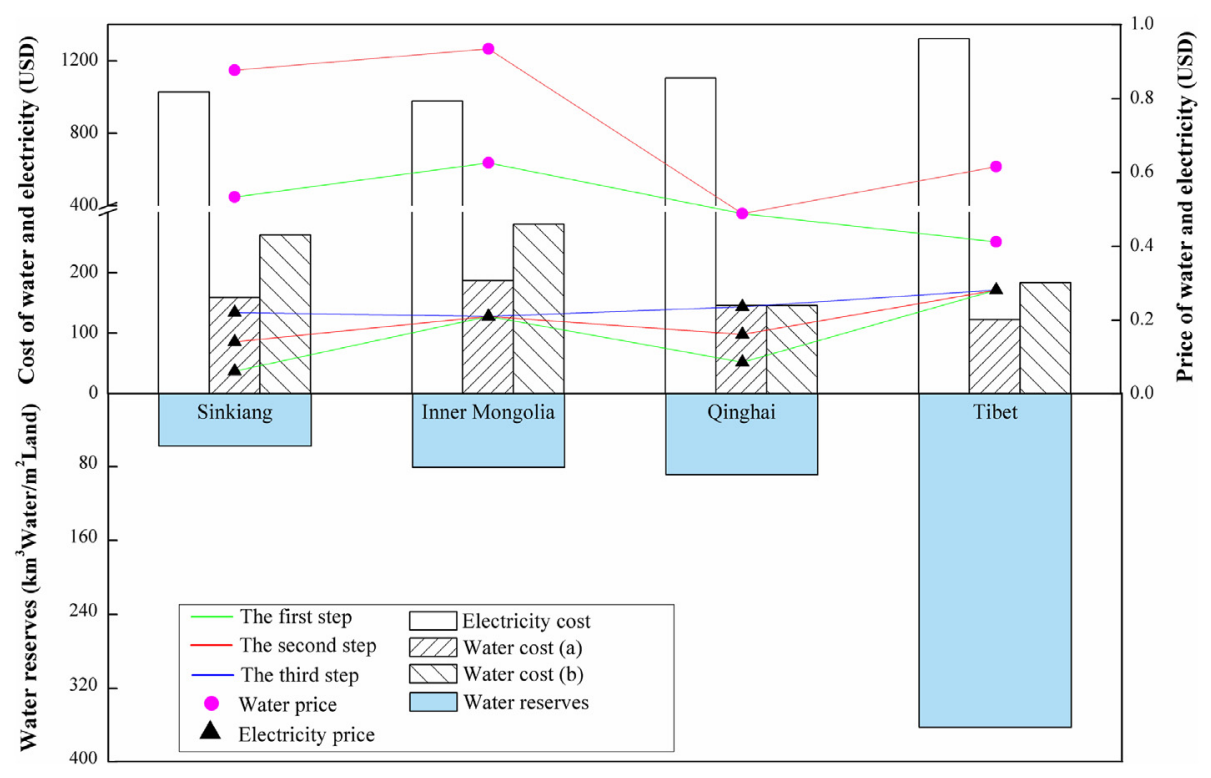

Fig. 6. Water-energy consumption and cost of lithium nanofiltration extraction technique in China.

lithium nanofiltration extraction technique due to the relatively large water reserves and low water prices.

The electricity consumption of Sinkiang and Qinghai is charge by step price while that of Inner Mongolia and Tibet is charged by the identical price. The electricity consumption cost for producing $1 \mathrm{t} \mathrm{Li}_{2} \mathrm{CO}_{3}$ in Sinkiang, Inner Mongolia, Qinghai and Tibet were 1028.58, 978.1, 1104.18 and 1321.38 USD, respectively. Different from water prices, electricity consumption costs of Tibet and Qinghai were relatively high.

The total cost of producing $1 \mathrm{t} \mathrm{Li}_{2} \mathrm{CO}_{3}$ in Sinkiang, Inner Mongolia, Qinghai and Tibet with the first step water price was about $1290.99,1258,1249.71$, and 1505.07 USD, respectively. It was more economically friendly to produce lithium carbonate in Qinghai province, where electricity prices were low and water reserves were large.
More than $60 \%$ global lithium production is extracted from brines (Tadesse et al., 2019). Therefore, new technologies for lithium recovery from brines have been widely explored (Flexer et al., 2018). However, information on LCA and sustainability of brine processing is still scarce. This study focused on LCA of lithium nanofiltration process with particular emphasis on the consumption of water and electricity during this process. Water-energy nexus is critical for many industries and the previous study also reported that energy consumption had effects on water use policies to subsequently affect the related industry (Xiang and Jia, 2019).

\section{Conclusions}

This study made an environmental and economic life cycle assessment of lithium nanofiltration extraction technique at a 
Table 2

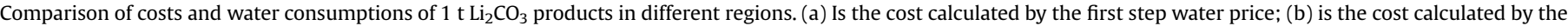
second step water price; (c) is the cost calculated by the third step electricity price.

\begin{tabular}{|c|c|c|c|c|c|c|c|}
\hline \multirow[t]{2}{*}{ Province } & \multirow{2}{*}{\multicolumn{2}{|c|}{ Water reserves (km3 Water/m2 Land) }} & \multicolumn{3}{|c|}{ Price of water $(\$)$} & \multicolumn{2}{|c|}{ Costs of $1 \mathrm{t} \mathrm{Li} 2 \mathrm{CO} 3$} \\
\hline & & & The first step & The second step & The third step & Cost (a) & Cost (b) \\
\hline Sinkiang & 58 & & 0.29 & 0.48 & 0.67 & 159.04 & 262.41 \\
\hline Inner Mongolia & 81 & & 0.34 & 0.51 & 1.03 & 186.87 & 279.90 \\
\hline Qinghai & 89 & & 0.27 & 0.27 & 0.27 & 145.52 & 145.52 \\
\hline Tibet & 362 & & 0.22 & 0.34 & 0.67 & 122.46 & 183.69 \\
\hline \multirow[t]{2}{*}{ Province } & & \multicolumn{4}{|l|}{ Price of electricity $(\$)$} & & Cost (c) \\
\hline & & The first step & \multicolumn{2}{|c|}{ The second step } & The third step & & \\
\hline Sinkiang & & 0.03 & \multicolumn{2}{|l|}{0.07} & 0.12 & & 1028.58 \\
\hline Inner Mongolia & & 0.11 & \multicolumn{2}{|l|}{0.11} & 0.11 & & 978.10 \\
\hline Qinghai & & 0.04 & \multicolumn{2}{|l|}{0.09} & 0.13 & & 1104.18 \\
\hline Tibet & & 0.15 & \multicolumn{2}{|l|}{0.15} & 0.15 & & 1321.38 \\
\hline
\end{tabular}

functional unit of $1 \mathrm{~kg} \mathrm{Li} 2 \mathrm{CO}_{3}$. Nanofiltration and hyperfiltration stages were the key process to generate environmental burdens and the major contributing factor was power consumption. The internal cost of this technique was much higher than the external cost. Direct water consumption was 22 times higher than indirect water consumption for this extraction technique with the biggest contributor of nanofiltration. Qinghai was more suitable to produce lithium carbonate than the other regions due to lower cost of water and energy. The results showed that improvement in resource utilization efficiency and water recycling were more effective to reduce the environmental governance costs and environmental load even the nanofiltration extraction technique was relatively environmentally-friendly. This study provides theoretical basis for the lithium industry especially in ecologically fragile regions in the world. It is also useful to understand the key process from environmental and economic perspectives. Further studies on LCA and LCC of different methods regarding lithium extraction from brine are also needed to enhance the representativeness of inventories.

\section{Declaration of competing interest}

The authors declare that they have no known competing financial interests or personal relationships that could have appeared to influence the work reported in this paper.

\section{CRediT authorship contribution statement}

Baolan Li: Methodology, Investigation, Writing - original draft. Jun Wu: Validation, Methodology, Conceptualization, Writing review \& editing, Supervision. Jian Lu: Conceptualization, Writing review \& editing.

\section{Acknowledgements}

This work was financially supported by National Natural Science Foundation of China (41671319), One Hundred Talents Program of Chinese Academy of Sciences (Y610061033 and Y629041021), Taishan Scholars Program of Shandong Province (No. tsqn201812116), Youth Innovation Team Project for Talent Introduction and Cultivation in Universities of Shandong Province, and Thousand Talents Plan of Qinghai Province (Y740171071). We also would like to thank the reviewers for their valuable comments and suggestions on the manuscript.

\section{References}

Aganovic, K., Smetana, S., Grauwet, T., Toepfl, S., Mathys, A., Van Loey, A., Heinz, V., 2017. Pilot scale thermal and alternative pasteurization of tomato and watermelon juice: an energy comparison and life cycle assessment. J. Clean. Prod. 141, 514-525. https://doi.org/10.1016/j.jclepro.2016.09.015.

Al-Shayji, K., Aleisa, E., 2018. Characterizing the fossil fuel impacts in water desalination plants in Kuwait: a Life Cycle Assessment approach. Energy 158 681-692. https://doi.org/10.1016/j.energy.2018.06.077.

Alcaina-Miranda, M.I., Barredo-Damas, S., Bes-Piá, A., Iborra-Clar, M.I., IborraClar, A., Mendoza-Roca, J.A., 2009. Nanofiltration as a final step towards textile wastewater reclamation. Desalination 240, 290-297. https://doi.org/10.1016/ j.desal.2008.02.028.

An, J.W., Kang, D.J., Tran, K.T., Kim, M.J., Lim, T., Tran, T., 2012. Recovery of lithium from Uyuni salar brine. Hydrometallurgy 117-118, 64-70. https://doi.org/ 10.1016/j.hydromet.2012.02.008.

Bergman, R.A., 1995. Membrane softening versus lime softening in Florida: a cost comparison update. Desalination 102, 11-24. https://doi.org/10.1016/00119164(95)00036-2.

Bonton, A., Bouchard, C., Barbeau, B., Jedrzejak, S., 2012. Comparative life cycle assessment of water treatment plants. Desalination 284, 42-54. https://doi:10. 1016/j.desal.2011.08.035.

Chang, D.N., Lee, C.K.M., Chen, C.H., 2014. Review of life cycle assessment towards sustainable product development. J. Clean. Prod. 83, 48-60.

Chaudhari, L.B., Murthy, Z.V.P., 2010. Treatment of landfill leachates by nanofiltration. J. Environ. Manage. 91, 1209-1217. https://doi.org/10.1016 j.jenvman.2010.01.007.

Cusenza, M.A., Bobba, S., Ardente, F., Cellura, M., Di Persio, F., 2019. Energy and environmental assessment of a traction lithium-ion battery pack for plug-in hybrid electric vehicles. J. Clean. Prod. 215, 634-649. https://doi.org/10.1016 j.jclepro.2019.01.056.

Flexer, V., Baspineiro, C.F., Galli, C.I., 2018. Lithium recovery from brines: a vital raw material for green energies with a potential environmental impact in its mining and processing. Sci. Total Environ. 639, 1188-1204. https://doi.org/10.1016/ j.scitotenv.2018.05.223.

Giagnorio, M., Steffenino, S., Meucci, L., Zanetti, M.C., Tiraferri, A., 2018. Design and performance of a nanofiltration plant for the removal of chromium aimed at the production of safe potable water. J. Environ. Chem. Eng. 6, 4467-4475. https:// doi.org/10.1016/j.jece.2018.06.055.

He, P.W., Feng, H.B., Hu, G.J., Hewage, K., Achari, G., Wang, C., Sadiq, R., 2020. Life cycle cost analysis for recycling high-tech minerals from waste mobile phones in China. J. Clean. Prod. 251, 119498. https://doi.org/10.1016/ j.jclepro.2019.119498.

Hong, J.L., Chen, W., Wang, Y.T., Xu, C.Q., Xu, X., 2014. Life cycle assessment of caustic soda production: a case study in China. J. Clean. Prod. 66, 113-120. https:// doi.org/10.1016/j.jclepro.2013.10.009.

Hong, J.L., Chen, W., Qi, C.C., Ye, L.P., Xu, C.Q., 2016. Life cycle assessment of multicrystalline silicon photovoltaic cell production in China. Sol. Energy 133, 283-293. https://doi.org/10.1016/j.solener.2016.04.013.

Islam, A., Ahmed, T., Awual, M.R., Rahman, A., Sultana, M., Aziz, A.A., Monir, M.U., Teo, S.H., Hasan, M., 2020. Advances in sustainable approaches to recover metals from e-waste-A review. J. Clean. Prod. 244, 118815. https://doi.org/ 10.1016/j.jclepro.2019.118815.

Jiang, S.Y., Zhang, L., Li, F.Y., Hua, H., Liu, X., Yuan, Z.W., Wu, H.J., 2020. Environmental impacts of lithium production showing the importance of primary data of upstream process in life-cycle assessment. J. Environ. Manage. 262, 110253. https://doi.org/10.1016/j.jenvman.2020.110253.

Kang, W.Q., Shi, L.J., Zhao, Y.J., Zhang, D.Y., Zhang, H.T., Wang, M., 2014. Preliminary test of separation of $\mathrm{Mg}^{2+} / \mathrm{Li}^{+}$in salt lake brine by nanofiltration. Inorg. Chem. Ind. 46, 22-24 (in Chinese).

Lipu, M.S.H., Hannan, M.A., Hussain, A., Hoque, M.M., Ker, P.J., Saad, M.H.M., Ayob, A. 2018. A review of state of health and remaining useful life estimation methods for lithium-ion battery in electric vehicles: challenges and recommendations. J. Clean. Prod. 205, 115-133. https://doi.org/10.1016/j.jclepro. 2018.09.065.

Liu, X.L., Wang, H.T., Chen, J., He, Q., Zhang, H., Jiang, R., Chen, X.X., Hou, P., 2010. Method and basic model for development of Chinese reference life cycle 
database. Acta Sci. Cirumst. 30, 2136-2144 (in Chinese).

Li, Y., Zhao, Y.J., Wang, H.Y., Wang, M., 2019. The application of nanofiltration membrane for recovering lithium from salt lake brine. Desalination 468, 114081 . https://doi.org/10.1016/j.jclepro.2014.07.050.

Marques, P., Garcia, R., Kulay, L., Freire, F., 2019. Comparative life cycle assessment of lithium-ion batteries for electric vehicles addressing capacity fade. J. Clean. Prod. 229, 787-794. https://doi.org/10.1016/j.jclepro.2019.05.026.

Manda, B.M.K., Worrell, E., Patel, M.K., 2014. Innovative membrane filtration system for micropollutant removal from drinking water-prospective environmenta LCA and its integration in business decisions. J. Clean. Prod. 72, 153-166. https://doi.org/10.1016/j.jclepro.2014.02.045.

NBS, 2019. National bureau statistics of China. http://www.h2o-china.com/price/ assessed 1 July 2019.

Oh, B.K., Choi, S.W., Park, H.S., 2017. Influence of variations in $\mathrm{CO}_{2}$ emission data upon environmental impact of building construction. J. Clean. Prod. 140, 1194-1203. https://doi.org/10.1016/j.jclepro.2016.10.041.

Shao, L.G., Jin, S.Z., 2020. Resilience assessment of the lithium supply chain in China under impact of new energy vehicles and supply interruption. J. Clean. Prod. 252, 119624. https://doi.org/10.1016/j.jclepro.2019.119624.

Shi, D., Zhang, L.C. Peng, X.W., Li, L.J., Song, F.G., Nie, F., Ji, L.M., Zhang, Y.Z., 2018 Extraction of lithium from salt lake brine containing boron using multistage centrifuge extractors. Desalination 441, 44-51. https://doi.org/10.1016/ j.desal.2018.04.029.

Song, J.F., Li, X.M., Zhang, Y.Y., Yin, Y., Zhao, B.L., Li, C.X., Kong, D.F., He, T., 2014 Hydrophilic nanoporous ion-exchange membranes as a stabilizing barrier for liquid-liquid membrane extraction of lithium ions. J. Membr. Sci. 471, 372-380. https://doi.org/10.1016/j.memsci.2014.08.010.
Stamp, A., Lang, D.J., Wäger, P.A., 2012. Environmental impacts of a transition toward e-mobility: the present and future role of lithium carbonate production. J. Clean. Prod. 23, 104-112. https://doi.org/10.1016/j.jclepro.2011.10.026.

Sun, S.Y., Cai, L.J., Nie, X.Y., Song, X.F., Yu, J.G., 2015. Separation of magnesium and lithium from brine using a Desal nanofiltration membrane. J. Water Process. Eng. 7, 210-217. https://doi.org/10.1016/j.jwpe.2015.06.012.

Swain, B., 2017. Recovery and recycling of lithium: a review. Sep. Purif. Technol. 172, 388-403. https://doi.org/10.1016/j.seppur.2016.08.031.

Tadesse, B., Makuei, F., Albijanic, B., Dyer, L., 2019. The beneficiation of lithium minerals from hard rock ores: a review. Miner. Eng. 131, 170-184. https:// doi.org/10.1016/j.mineng.2018.11.023.

Xiang, D., 2016. reportTechno-Economic Analysis and Life Cycle Assessment of CoalTo-Olefins Processes. Ph.D. thesis. South China University of Technology. Guangzhou, China.

Xing, D., Li, G., Liu, X., Guo, C., Yang, S.Y., Qian, Y., 2016. Water consumption analysis of olefins production from alternative resources in China. J. Clean. Prod. 139, 146-156. https://doi.org/10.1016/j.jclepro.2016.08.031.

Xiang, X.Z., Jia, S.F., 2019. China's water-energy nexus: assessment of water related energy use. Resour. Conserv. Recycl. 144, 32-38. https://doi.org/10.1016/ j.resconrec.2019.01.009.

Ye, L.P., Hong, J.L., Ma, X.T., Qi, C.C., Yang, D.L., 2018. Life cycle environmental and economic assessment of ceramic tile production: a case study in China. J. Clean. Prod. 189, 432-441. https://doi.org/10.1016/j.jclepro.2018.04.112.

Yu, J.Q., Gao, C.L., Cheng, A.Y., Liu, Y., Zhang, L.S., He, X.H., 2013. Geomorphic, hydroclimatic and hydrothermal controls on the formation of lithium brine deposits in the Qaidam Basin, northern Tibetan Plateau, China. Ore Geol. Rev. 50, 171-183. https://doi.org/10.1016/j.oregeorev.2012.11.001. 